\title{
Thermal performance in a tubular heat exchanger with delta- winglets
}

\author{
Pattarapan Tongyote, Pongjet Promvonge*, Nattawoot Depaiwa and Withada Jedsadaratanachai \\ Mechanical Engineering Dept., Faculty of Engineering, King Mongkut's Institute of Technology Ladkrabang, Bangkok, Thailand
}

\begin{abstract}
The paper presents an experimental heat transfer enhancement study in a tubular heat exchanger fitted with delta-winglets. The experimental work was conducted by varying the airflow rate in the test tube having a constant wall heat-flux for turbulent regime, Reynolds number (Re) from 5200 to 23,000. Effects of three pitch ratios ( $\mathrm{PR}=P / D=1.5,2.0$ and 3.0) and two attack angles, $\alpha=45^{\circ}$ and $60^{\circ}$, of the winglets at a single blockage ratio $(\mathrm{BR}=b / D=0.15)$ on thermal characteristics are examined. The experimental results show that the winglet-inserted tube yields, respectively, the heat transfer, friction factor and thermal performance in the form of TEF around 1.99-4.08, 4.9-14.3 times higher than the plain tube and 0.85-1.85, depending on the operating condition.
\end{abstract}

\section{Introduction}

Vortex flows have been extensively applied in thermal systems to increase their performance of such systems in industrial applications, for example, vortex tube [1], solar air heater $[2,3]$, heat exchanger systems $[4,5]$, etc. Vortex devices such as rib/baffle [6,7], coiled-wire [8,9], conical nozzles [10-13], twisted tape [14-16], fined tape $[17,18]$, and winglet [19-21] are commonly employed for heat transfer enhancement in heating or cooling passages. Thermal improvement by those devices relies on induced vortex in the flow of fluid. The vortex generators (VGs) usually are inserted into the flow field to provide an interruption of boundary layer development and to accelerate the flow velocity, especially for tangential velocity, leading to increasing more turbulence intensity and then, causing the enhancement of the heat transfer rate. There have been many reports on the influences of insertion of vortexflow devices in heating or cooling tubes/ducts on heat transfer, friction loss and thermal performance.

The application of rib/baffle and coiled-wire to promote heat transfer in a tube/duct regarded as a traditional style, is very plentiful in the literature. Promvonge and Eiamsa-ard [10-13] experimentally examined thermal characteristics in a tube with conicalnozzle inserts and pointed that the nozzles provided the considerable heat transfer over the plain tube around 250 to $350 \%$ depending on nozzle arrangements. Thermal behaviors in a tube contained with various twisted tapes were investigated and performance improvement by using those devices were reported in [14-16]. Promvonge et al. $[17,18]$ experimentally and numerically studied on thermal characteristics in a square duct with angle-finned tape inserts and suggested that the smallest fin pitch ratio provides the maximum Nusselt number, friction factor and thermal performance. The turbulent convection heat transfer in a round tube with winglet insert was investigated as offered by $[18,19]$. Recently, Tamna et al. [21] numerically studied thermal performance in a round tube inserted with winglet-pairs placed on two tape sides before insertion. High thermal improvement including vortex-flow structure was reported.

In the mentioned literature review, a lot of vortexflow devices or VGs have been offered to improve thermal performance of the heat exchanger tube. Among the mentioned devices, the winglets as reported in [21] is considered to be investigated due to its lowest pressure loss apart from easy manufacture. In the present work, delta winglet pairs are introduced. Due to curved surface of the round tube, the winglet pairs are placed repeatedly on double sides of a flat tape used as the support of winglets before inserting the tape into the test tube. The experimental results using air as the test fluid are presented for turbulent flow, Reynolds number ranging from 5200 to 23,000 in the current study.

\section{Experimental procedure}

Fig. 1 shows a schematic diagram of the experimental apparatus. In the figure, room air supplied by a $1.5-\mathrm{kW}$ blower entered into an orifice flow-meter before passing through the test section. The volumetric rate of airflow in the system was measured by the flow-meter, built under ASME standard [22]. The pressure drop across the orifice was measured using an inclined manometer. The volumetric airflow rate was varied by adjusting the speed of the blower motor through an inverter.

The copper test tube with 50-mm inner diameter $(D)$ was $3000-\mathrm{mm}$ long, included the test section $(L)$ of $1600-\mathrm{mm}$ as demonstrated in Fig. 1. Using continually

${ }^{*}$ Corresponding author: kpongjet@gmail.com 
winding flexible electrical wire around the tube was suggested to yield a uniform heat-flux condition. The outer surface of the test tube was well insulated to minimize convective heat loss to the surroundings. The inlet and outlet temperatures $\left(T_{\mathrm{i}}\right.$ and $\left.T_{\mathrm{o}}\right)$ of the bulk air were measured at certain points with a multi-channel temperature measurement unit in conjunction with the RTD PT-100 type temperature sensors. The wall temperatures $\left(T_{\mathrm{w}}\right)$ were measured by using sixteen Ttype thermocouples mounted on the outer tube surface and located equally on the top wall along the test section. Two static pressure taps coupled with a digital manometer were used to measure pressure drops across the test tube. The measurement was done twice for all cases for examining its repeatability.

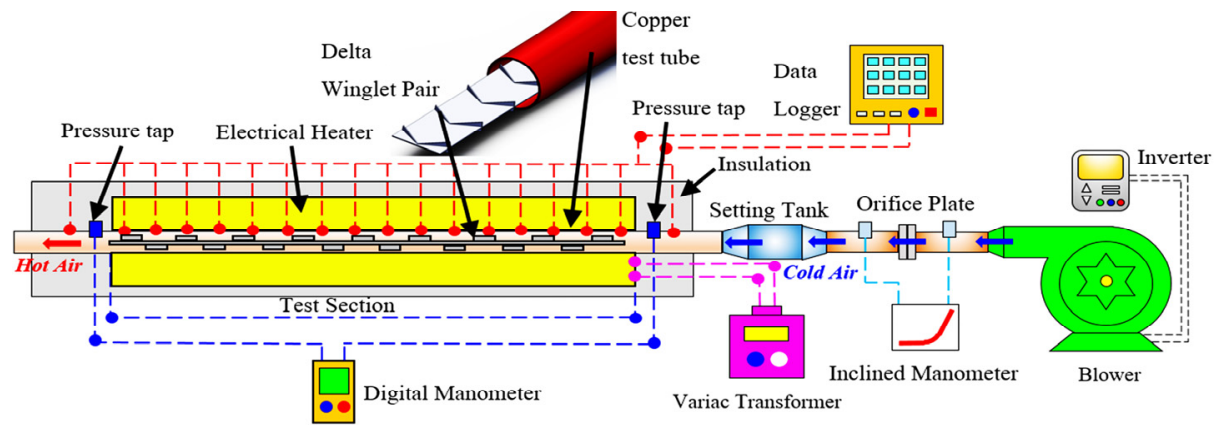

Fig. 1. Schematic diagram of experimental setup.

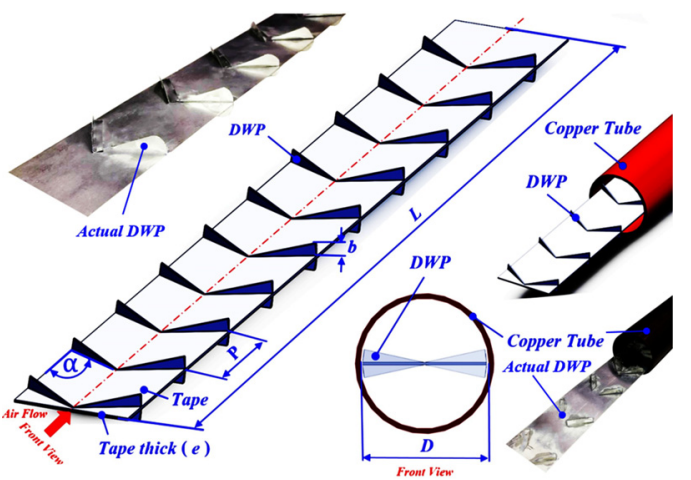

Fig. 2. Arrangements of delta winglet pairs (DWP) on a tape.

Fig. 2 portrays the arrangement of delta-winglet pairs (DWP) used in the present work. The winglet was made of a $0.5-\mathrm{mm}$ aluminium strip and formed it to be delta winglet before attaching it on a tape by using hot glue as shown in Fig. 2. Each winglet was $19.8 \mathrm{~mm}$ in length $(l)$ while the tape was $1600-\mathrm{mm}$ long and $0.5-\mathrm{mm}$ thick (e). The DWPs with a fixed blockage ratio $(\mathrm{BR}=b / D=0.15)$ were mounted repeatedly on both tape sides for two angles of attack $\left(\alpha=45^{\circ}\right.$ and $\left.60^{\circ}\right)$ and three relative pitches $(\mathrm{PR}=P / D=1.5,2.0$ and 3.0) as displayed in Fig. 2.

\section{Data reduction}

Parameters of interest included Reynolds number (Re), heat transfer rate (Nusselt number, $\mathrm{Nu}$ ), pressure drop (friction factor, f), and thermal enhancement factor (at the same pumping power), are described in this section. The Re is given by

$$
\operatorname{Re}=U D / v
$$

where $U$ and $v$ are the mean air velocity in the test tube and kinematic viscosity of air, respectively.

The friction factor $(f)$ computed by pressure drop across the length of the test section $(L)$ is written as

$$
f=\frac{\Delta p}{(L / D) \rho U^{2} / 2}
$$

In the experiment, air flowed into the test tube having a uniform heat-flux. In a steady state condition, the heat transfer in the test tube is assumed to be equal to the heat loss which is expressed as:

$$
Q_{\text {air }}=Q_{\text {conv }}
$$

where

$$
Q_{\text {air }}=\dot{m} C_{\text {p,air }}\left(T_{\mathrm{o}}-T_{\mathrm{i}}\right)
$$

The heat transfer by the test tube is written by

$$
Q_{\text {conv }}=h A\left(\widetilde{T}_{\mathrm{w}}-T_{\mathrm{b}}\right)
$$

in which

$$
T_{b}=\left(T_{o}+T_{i}\right) / 2
$$

and

$$
\widetilde{T}_{\mathrm{w}}=\sum T_{\mathrm{w}} / 16
$$

where $T_{\mathrm{w}}$ is local wall temperature along the tube. The average wall temperature, $\widetilde{T}_{\mathrm{w}}$ is evaluated from 16 local wall temperatures lined equally between the inlet and the exit of test tube. The average heat transfer coefficient $(h)$ and mean Nusselt number $(\mathrm{Nu})$ are estimated as follows:

$$
\left.h=\dot{m} C_{\mathrm{p}, \text { air }}\left(T_{\mathrm{o}}-T_{\mathrm{i}}\right) / A \widetilde{T}_{\mathrm{w}}-T_{\mathrm{b}}\right)
$$


The heat transfer is computed in the form of $\mathrm{Nu}$ which can be obtained by

$$
N u=h D / k
$$

All thermo-physical properties of air are determined at the overall bulk air temperature $\left(T_{\mathrm{b}}\right)$ from Eq. (6).

Thermal enhancement factor (TEF) defined as the ratio of the, $h$ of an inserted tube to that of a smooth tube, $h_{0}$, at an identical pumping power (pp) is written as:

$$
\mathrm{TEF}=\left.\frac{h}{h_{0}}\right|_{\mathrm{pp}}=\left.\frac{\mathrm{Nu}}{\mathrm{Nu}_{0}}\right|_{\mathrm{pp}}=\left(\frac{\mathrm{Nu}}{\mathrm{Nu}_{0}}\right)\left(\frac{f_{0}}{f}\right)^{1 / 3}
$$

where $\mathrm{Nu}_{0}$ and $f_{0}$ are Nusselt number and friction factor of the plain tube, respectively.

\section{Results and discussion}

\subsection{Verification of plain tube}

The validation of the present heat transfer $(\mathrm{Nu})$ and friction loss $(f)$ of the plain tube is made by comparing them with those from the published correlations [23] of Dittus-Boelter, Eq. (11) and Blasius, Eq. (12) as shown in Fig. 3. In the figure, both $\mathrm{Nu}$ and $f$ are seen to agree very well within $6 \%$ with those from the correlations.

Dittus-Boelter correlation,

$$
\mathrm{Nu}=0.023 \operatorname{Re}^{4 / 5} \operatorname{Pr}^{0.4}
$$

Blasius correlation,

$$
f=0.316 \mathrm{Re}^{-0.25}
$$

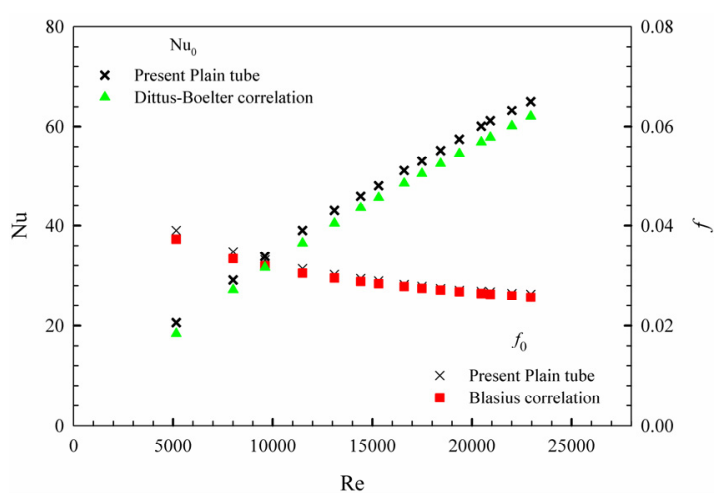

Fig. 3. Verification of $\mathrm{Nu}$ and $f$ for plain tube.

\subsection{Heat transfer result}

The variation of Nusselt number ratio $\left(\mathrm{Nu} / \mathrm{Nu}_{0}\right)$ with $\mathrm{Re}$ for DWP tape inserts is displayed in Fig. 4. In the figure, the $\mathrm{Nu} / \mathrm{Nu}_{0}$ shows the decreasing trend with the rise in $\mathrm{Re}$ for all cases. It is noted that the highest $\mathrm{Nu} / \mathrm{Nu}_{0}$ around 4.08 times is seen for $\alpha=60^{\circ}$ and $P R=1.5$ while the lowest one around 1.99 is at $\alpha=45^{\circ}$ and $\mathrm{PR}=3.0$. This is because of interrupting more often the flow at $\mathrm{PR}=1.5$ and of stronger vortex strength at $\alpha=60^{\circ}$ leading to more efficient heat transfer between the working fluid and the heated wall surface. The average increases in $\mathrm{Nu} / \mathrm{Nu}_{0}$ for $\alpha=45^{\circ}$ and $60^{\circ}$ are about 3.04, 2.48, and 2.33; and 3.22, 2.90 and 2.73 times at $P R=1.5,2.0$ and 3.0, respectively. The increase in $\mathrm{Nu} / \mathrm{Nu}_{0}$ for $\alpha=60^{\circ}$ is about $12 \%$ in comparison with that for $\alpha=45^{\circ}$.

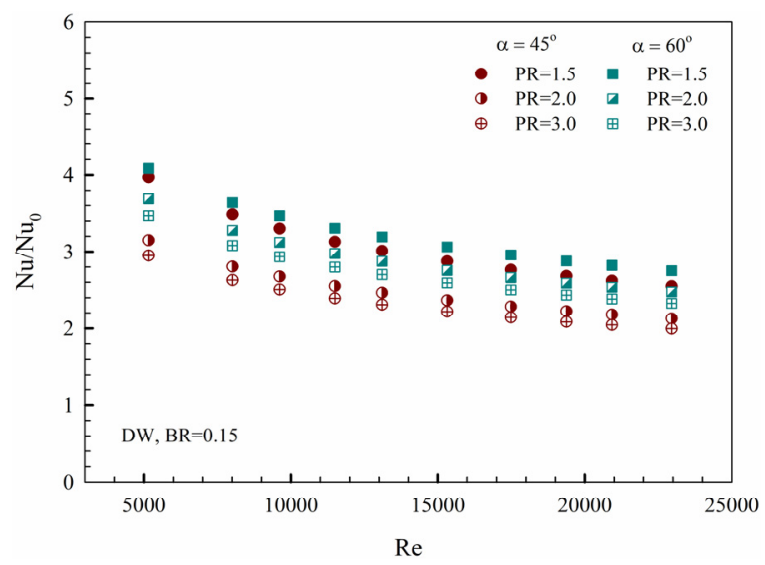

Fig. 4. Variation of $\mathrm{Nu} / \mathrm{Nu}_{0}$ with $\mathrm{Re}$ for various $\mathrm{DWP}$ tapes

\section{3 friction factor result}

The variation of friction factor ratio $\left(f / f_{0}\right)$ with Re for DWP tape inserts is depicted in Fig. 5. It is found that the DWP tape yields an extreme increase in $f$ due to the dissipation of dynamic pressure, larger surface area and the reverse/swirl flow. The $f / f_{0}$ shows the uptrend with increasing $\operatorname{Re}$ and $\alpha$ values while gives the downtrend with rising PR value. The mean increases in $f / f_{0}$ for $\alpha=$ $45^{\circ}$ and $60^{\circ}$ are about 10.95, 7.67, and 5.99; and 13.01, 8.46 and 6.51 times at $\mathrm{PR}=1.5,2.0$ and 3.0, respectively. The DWP tape at $\alpha=60^{\circ}$ and $P R=1.5$ gives the highest $f / f_{0}$ of about 14.3 times while the lowest of about 4.9 times is seen at $\alpha=45^{\circ}$ and $\mathrm{PR}=3.0$, similar to the $\mathrm{Nu} / \mathrm{Nu}_{0}$ case. The mean $f l f_{0}$ for the DWP tape at $\mathrm{PR}=1.5$ is seen to be higher than the one at $\mathrm{PR}=2.0$ and 3.0 around 12 and $25 \%$. However, the $f / f_{0}$ at $\alpha=60^{\circ}$ is higher than that at $\alpha=45^{\circ}$ around $20 \%$.

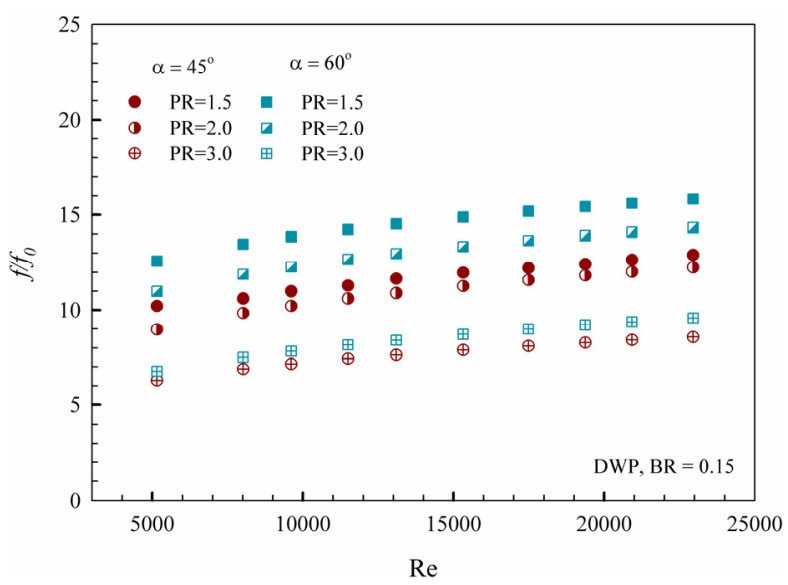

Fig. 5. Variation of $f l f_{0}$ with Re for various DWP tapes 


\subsection{Thermal performance}

Figure 6 illustrates the variation of thermal enhancement factor (TEF) with Re for all inserts. The TEF is obtained by using $\mathrm{Nu}$ and $f$ data of the inserted tube and the plain tube under a constant pumping power as shown in Eq. (10). In the figure, TEF displays the increasing trend with the rise in Re for all cases. The highest TEF around 1.85 is seen for $\alpha=45^{\circ}$ and $P R=1.5$ at the lowest Re value while the minimum one around 0.88 is at $\alpha=60^{\circ}$ and $\mathrm{PR}=3.0$. The best case is found at $\alpha=45^{\circ}$ and $P R=1.5$ since TEF is higher than unity for all Re values.

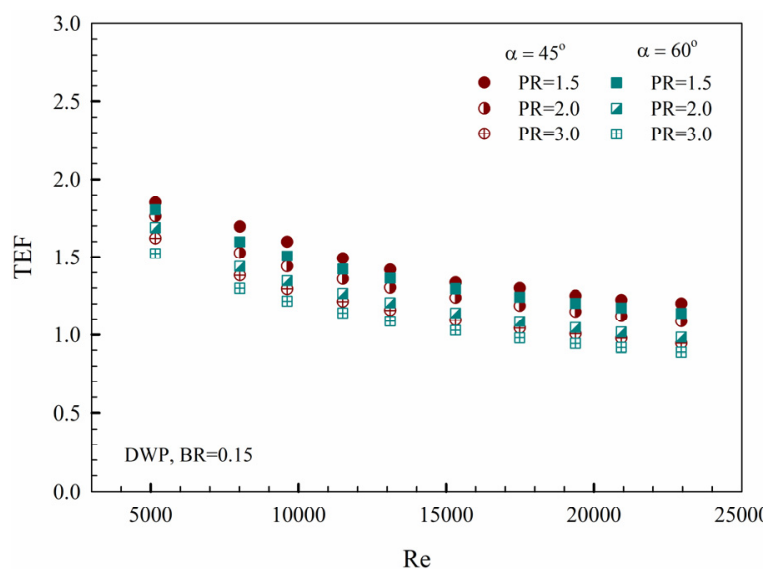

Fig. 6. Effect of DWP insert on TEF.

\section{Conclusion}

An experimental study on thermal behaviors in a circular tube contained with DWP tapes having three PR and two $\alpha$ values was conducted for turbulent flow, $\mathrm{Re}=$ 5200-23,000 under a constant heat-flux condition. The $\mathrm{Nu} / \mathrm{Nu}_{0}$ tends to decrease whereas $f / f_{0}$ increases with the rise in $\mathrm{Re}$ and $\mathrm{PR}$ values but both show the opposite trend with the increment in $\alpha$ value. The DWP tape insert provides the increases in $\mathrm{Nu} / \mathrm{Nu}_{0}$ and $f l f_{0}$ around $1.99-$ 4.08 and $4.9-14.3$ times. Also, the highest TEF of about 1.85 is found for $\alpha=45^{\circ}$ and $\mathrm{PR}=1.5$ at the lowest Re.

\section{References}

1. S. Eiamsa-ard, K. Wongcharee, P. Promvonge, Int. Commun. Heat Mass Transf., 37, 156-162 (2010)

2. P. Promvonge, S. Eiamsa-ard, Int. Commun. Heat Mass Transf., 34, 838-848 (2007)

3. P. Promvonge, Int. Commun. Heat Mass Transf., 37, 835-840 (2010)
4. S. Skullong, C. Thianpong, P. Promvonge, Heat Mass Transf., 51, 1475-1485 (2015)

5. S. Liu, M. Sakr, Renew. Sustain. Energy Rev., 19, 64-81(2013)

6. A. Tandiroglu, Int. J. Heat Mass Transf., 49, 15591567 (2006)

7. S. Skullong, C. Thianpong, N. Jayranaiwachira, P. Promvonge, Chem. Eng. Process. Process Intensif., 99, 58-71 (2016)

8. P. Promvonge, Int. Commun. Heat Mass Transf., 35, 623-629 (2008)

9. P. Promvonge, Energy Convers. Manage., 49, 980987 (2008)

10. P. Promvonge, S. Eiamsa-ard, Int. Commun. Heat Mass Transf., 34, 72-82 (2007)

11. P. Promvonge, S. Eiamsa-ard, Int. Commun. Heat Mass Transf., 34, 838-848 (2007)

12. P. Promvonge, S. Eiamsa-ard, Exp. Therm. Fluid Sci., 32, 332-40 (2007)

13. P. Promvonge, S. Eiamsa-ard, Energy Convers. Manage., 47, 2867-82 (2006)

14. S. Eiamsa-ard, C. Thianpong, P. Promvonge, Int. Commun. Heat Mass Transf., 33, 1225-1233 (2006)

15. P. Promvonge, S. Pethkool, M. Pimsarn, C. Thianpong, Int. Commun. Heat Mass Transf., 39, 953-959 (2012)

16. C. Thianpong, P. Eiamsa-ard, P. Promvonge, S. Eiamsa-ard, Energy Procedia, 14, 1117-1123 (2012)

17. P. Promvonge, S. Skullong, S. Kwankaomeng, C. Thianpong, Int. Commun. Heat Mass Transf., 39, 617-624 (2012)

18. P. Promvonge, S. Skullong, S. Kwankaomeng, C. Thianpong, Int. Commun. Heat Mass Transf., 39, 625-633 (2012)

19. S. Eiamsa-ard, K. Wongcharee, P. Promvonge, C. Thianpong, Appl. Therm. Eng., 30, 310-318 (2010)

20. S. Chokphoemphun, M. Pimsarn, C. Thianpong, P. Promvonge, Chin. J. Chem. Eng., 23, 605-614 (2015)

21. S. Tamna, S. Sripattanapipat, P. Promvonge, Energy Procedia, 100, 518-521 (2016)

22. ASME, Standard Measurement of fluid flow in pipes using orifice, nozzle and venture, (United Engineering Center, 1984)

23. Incropera, F.P. Witt, P.D. Bergman, A.S. Lavine, Fundamentals of heat and mass transfer, (JohnWiley \& Sons, 2006) 